\title{
ESTUDOS SOBRE MÁQUINAS E SISTEMAS ANCESTRAIS EM ENGENHARIA NA UNIFEI
}

DOI: 10.37702/2175-957X.COBENGE.2021.3520

Adinele Gomes Guimarães - adinele@unifei.edu.br

Universidade Federal de Itajubá

Av BPS 1303

37500-903 - Itajubá - MG

Pablo Levi de Freitas Pinto - pablolevidefreitas@gmail.com

Universidade Federal de Itajubá

Rua Nova Pádua 38

12226-795 - São José dos Campos - SP

Tatiana Meirelles Faria - tatianameirelles@unifei.edu.br

Universidade Federal de Itajubá

Rua Zilda de Barros Franco 21

37553-477 - Pouso Alegre - MG

José Henrique Mouallem Gonçalves - josehmg@unifei.edu.br Universidade Federal de Itajubá

Rua Coronel Francisco Brás 800

37500-052 - Itajubá - MG

Lucas Neves Braga Soares Ribeiro - Lucas.neves.ribeiro@unifei.edu.br Universidade Federal de Itajubá

Avenida BPS 492

37500-177 - Itajubá - MG

Victor Franklin de Alencar Laufer - victorlaufer@unifei.edu.br Universidade Federal de Itajubá

Rua Icatu 300

12237-010 - São José dos Campos - SP

Carlos Barreira Martinez - cmartinez@unifei.edu.br

Universidade Federal de Itajubá

Avenida Bps 492

37500-177 - Itajuba - MG 
Resumo: $O$ princípio básico de funcionamento de equipamentos ancestrais muitas vezes é o mesmo dos modernos sistemas utilizados em engenharia atualmente. Entendendo que as soluções utilizadas no passado fornecem fortes indícios sobre alternativas de engenharia, que podem servir para resolver problemas contemporâneos e desenvolver habilidades que facilitam a compreensão de mecanismos e estruturas atuais, procurou-se desenvolver um projeto envolvendo alunos de graduação com o objetivo de apresentar um conjunto de modelos de equipamentos ancestrais, representativas das tecnologias desenvolvidas por civilizações anteriores à atual, como instrumento de ensino na engenharia. Os alunos eram orientados no desenvolvimento das atividades, distribuídas nas seguintes etapas: (i) seleção de um mecanismo e/ou estrutura considerada representativas de uma determinada época ou civilização por meio de levantamento bibliográfico; (ii) elaboração dos projetos dos modelos reduzidos com base nos dados levantados e (iii) construção e ensaio dos elementos selecionados. Na primeira fase do projeto foram selecionados os seguintes equipamentos e sistemas: Ponte de Langlois, Grua do séc. XV, Máquina Elevadora Romana, Canhão Naval séc. XVIII, Parafuso de Arquimedes e Moinho d'água séc. III a.C.. As máquinas e sistemas ancestrais construídos neste projeto deram início a um conjunto de pequenas estruturas que constituem o núcleo de uma coleção que ficará à disposição de professores dos cursos de graduação em engenharia e que poderão ser utilizados nas aulas como ferramenta de ensino. As peças produzidas compõem um acervo técnico inédito na UNIFEI e permitiram ao grupo de alunos envolvidos entenderem algumas das limitações do passado visualizando os caminhos adotados e as soluções encontradas pelos engenheiros em diversas épocas da nossa história.

Palavras-chave: história da engenharia, equipamentos antigos, modelos reduzidos, 


\section{ESTUDOS SOBRE MÁQUINAS E SISTEMAS ANCESTRAIS EM ENGENHARIA NA UNIFEI}

\section{INTRODUÇÃO}

A história da civilização é um caminho trilhado sobre máquinas e estruturas. Os primeiros agrupamentos humanos se utilizaram de técnicas de construção e de equipamentos que amplificaram a força humana e permitiram que o meio ambiente fosse conformado de acordo com a necessidade das civilizações locais. Para modificar o meio local é necessário fazer ao menos três operações, quais sejam: o deslocamento de materiais, a medição de distâncias e a estimativa de alturas. As duas últimas operações foram feitas no passado por meio de instrumentos que nada tem de primitivo e são, na verdade, um testemunho de inteligência e capacidade de abstração. Como exemplo destes instrumentos pode ser citado o dioptra, que era utilizado desde o século 4 a.C. para medição de ângulos horizontais (ADAM, J. P. , 1994). Alguns autores consideram que o dioptra pode ser entendido como o primeiro teodolito (GALLO, I.M., 2006). Pela Figura 1, pode-se observar a semelhança desse instrumento com o teodolito mecânico, empregado ainda hoje na determinação de ângulos horizontais e verticais e que, indiretamente, permite medir distâncias entre dois pontos.

Figura 1 - Reconstruções gráficas (a) dioptra feita por Venturi em 1814, (b) dioptra adaptado com descrições de Heron e (c) teodolito com leitura externa e bússola para orientação magnética.

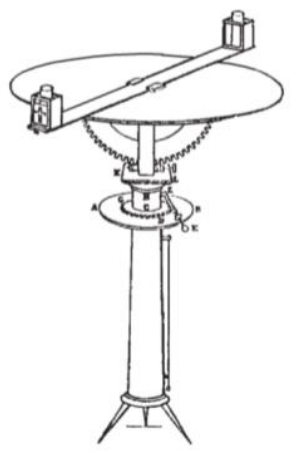

(a)

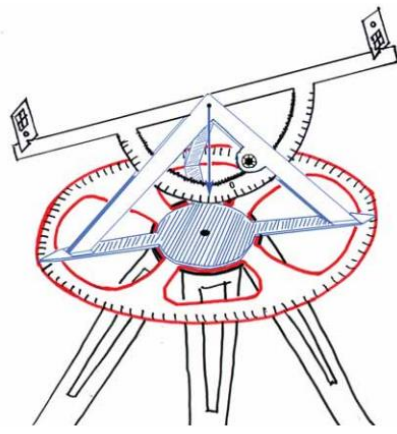

(b)

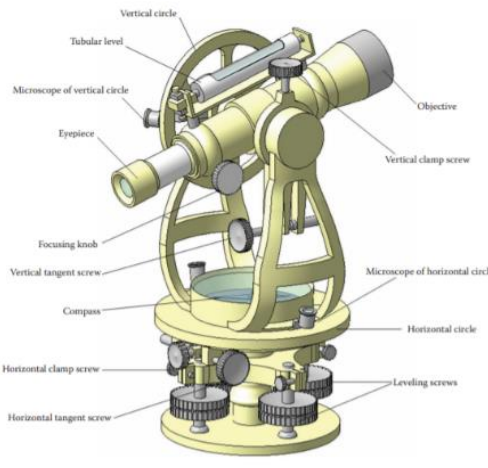

(c)

Fonte: (LEONID NADOLINETS , EUGENE LEVIN , DAULET AKHMEDOV, 2017)

O deslocamento de material e o seu posicionamento nas estruturas e construções eram feitos por meio de gruas, guindastes e carretas de carga, que eram transportados por vias pavimentadas cuja forma construtiva ainda é bastante próxima das estradas atuais. Já as fundações eram feitas por meio da cravação de estacas de madeira que permitiram a expansão da ocupação de vastas áreas na região do Mar Mediterrâneo e no Mundo Romano. Observa-se que o princípio básico de funcionamento desses equipamentos ancestrais é o mesmo dos modernos sistemas utilizados em engenharia atualmente, como pode ser visualizado na Figura 2(a) que apresenta um sistema de elevação de carga ancestral e na Figura 2(b) que mostra o núcleo de uma bomba hidráulica conhecida como parafuso de Arquimedes que foi utilizada para elevação de água desde o século 2 a.C. 
Figura 3 - Exemplos de mecanismos ancestrais (a) grua romana e (b) núcleo de bomba de Arquimedes.

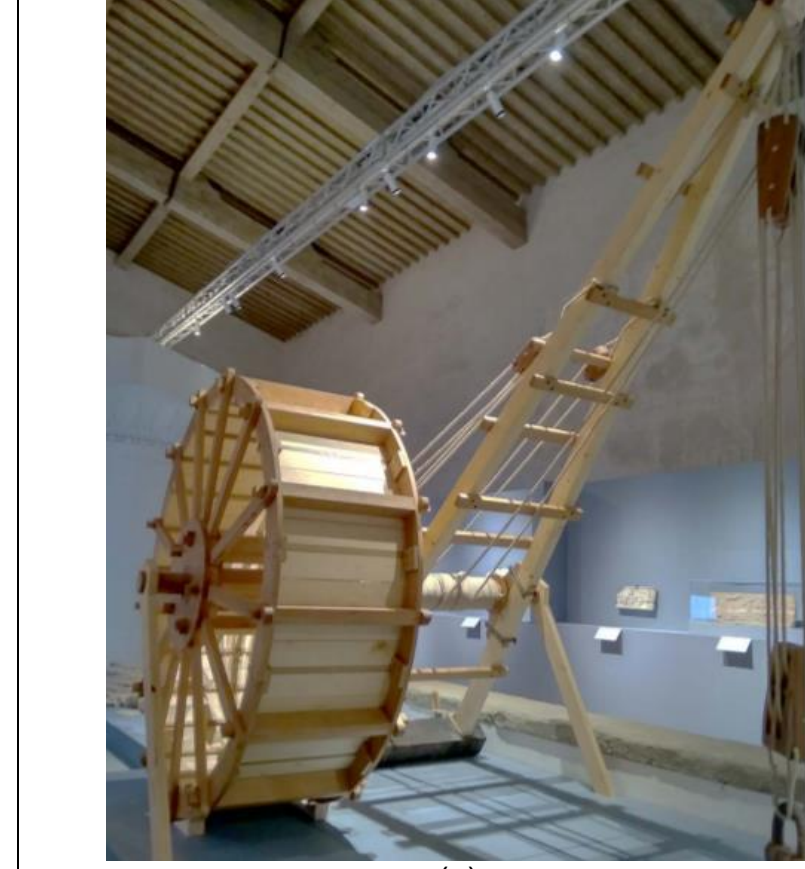

(a)

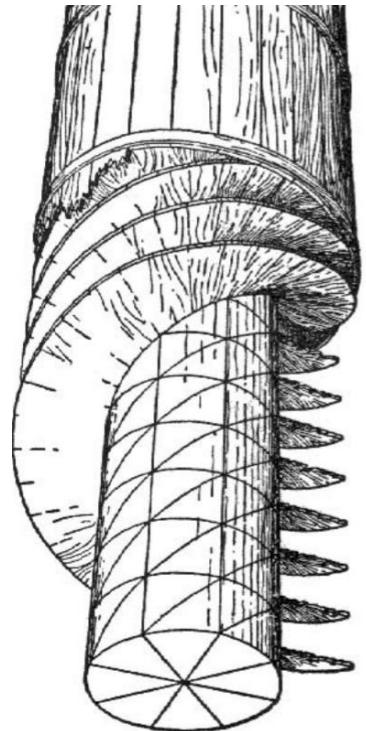

(b)

Fonte: Di Pasquae, 2019 apud (CECCARELLI, 2020).

Fonte: Vitruvius apud (RORRES, 2000)

Entendendo que os sistemas e soluções utilizadas no passado fornecem fortes indícios sobre alternativas de engenharia, que podem servir para solucionar problemas contemporâneos e desenvolver habilidades que facilitam a compreensão de mecanismos e estruturas atuais, procurou-se desenvolver um projeto envolvendo alunos de graduação que objetivou apresentar um conjunto de modelos de equipamentos ancestrais, representativos das tecnologias desenvolvidas por civilizações anteriores à atual, como instrumento de ensino na engenharia. Fez-se isso pois se considera que a qualidade de um curso de engenharia não decorre apenas dos docentes e dos espaços equipados e confortáveis, mas depende muito da qualidade e da motivação do estudante que nele ingressa (BAZZO e PEREIRA, 2006). Outro objetivo foi tentar motivar e inspirar os estudantes de engenharia, promovendo um processo educacional a partir do resgate de experiências ascendentes.

\section{METODOLOGIA}

As atividades do projeto foram realizadas inicialmente nas disciplinas EC/115 Tópicos Sobre História da Engenharia e EME051 - História da Engenharia Mecânica, oferecidas, respectivamente, para os cursos de graduação em Engenharia Civil e Engenharia Mecânica da Universidade Federal de Itajubá (UNIFEI). Nas primeiras aulas, os grupos de alunos tinham um nivelamento acerca do projeto e em seguida eram orientados no desenvolvimento das atividades, distribuídas nas seguintes etapas: (i) seleção de um mecanismo e/ou estrutura consideradas representativas de uma determinada época ou civilização por meio de levantamento bibliográfico; (ii) elaboração dos projetos dos modelos reduzidos com base nos dados levantados e (iii) construção e ensaio dos elementos selecionados. 


\subsection{Seleção dos equipamentos ancestrais}

Os objetos de estudo são mecanismos, estruturas e sistemas construtivos representativos de uma civilização e que cobrem alguns séculos de história, havendo assim uma diversidade de modelos que poderiam ser reproduzidos. Na primeira fase do projeto foram selecionados os seguintes equipamentos e sistemas: Ponte de Langlois (Figura 4), Grua do séc. XV (Figura 5), Máquina Elevadora Romana (Figura 6), Moinho d'água séc. III a.C. (Figura 7), Bicicleta de DaVinci (Figura 8) e Bate-estaca Romana (Figura 9).

A Ponte de Langlois era uma ponte levadiça de viga dupla em Arles, na França, que foi o tema de várias pinturas de Vincent van Gogh em 1888, sendo uma das onze pontes levadiças construídas por um engenheiro holandês ao longo do canal de Arles até Port-de-Bouc. Em 1930, a ponte levadiça original foi substituída por uma estrutura de concreto armado que, em 1944, foi explodida pelos alemães em retirada que destruíram todas as outras pontes ao longo do canal, exceto a de Fos. A ponte Fos foi desmontada em 1959 com o objetivo de realocá-la no local da ponte Langlois, mas como resultado de dificuldades estruturais foi finalmente remontada na eclusa de Montcalde, vários quilômetros de distância do local original. A ponte reconstruída foi chamada Pont Van Gogh (WIKIPEDIA CONTRIBUTORS, 2020).

Figura 4 - Ponte de Langlois (a) ponte original (1902) e (b) ponte realocada e renomeada Pont Van-Gogh

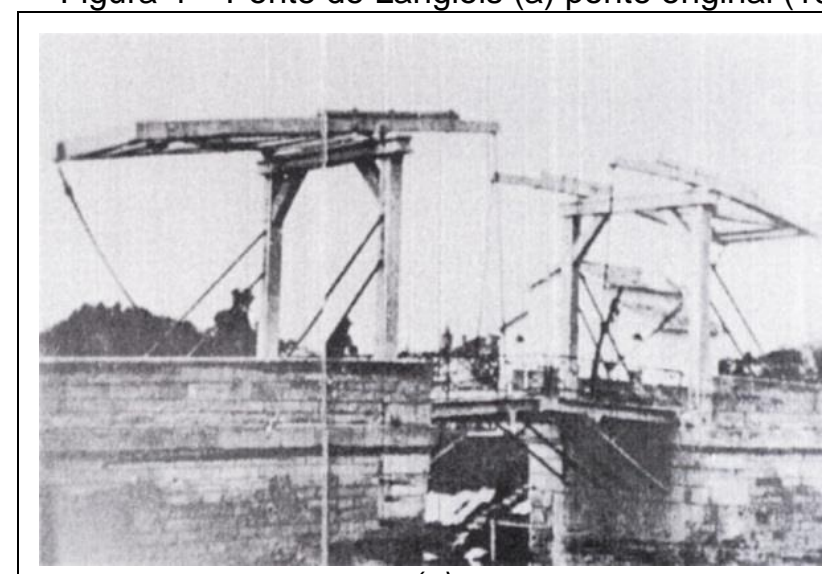

(a)

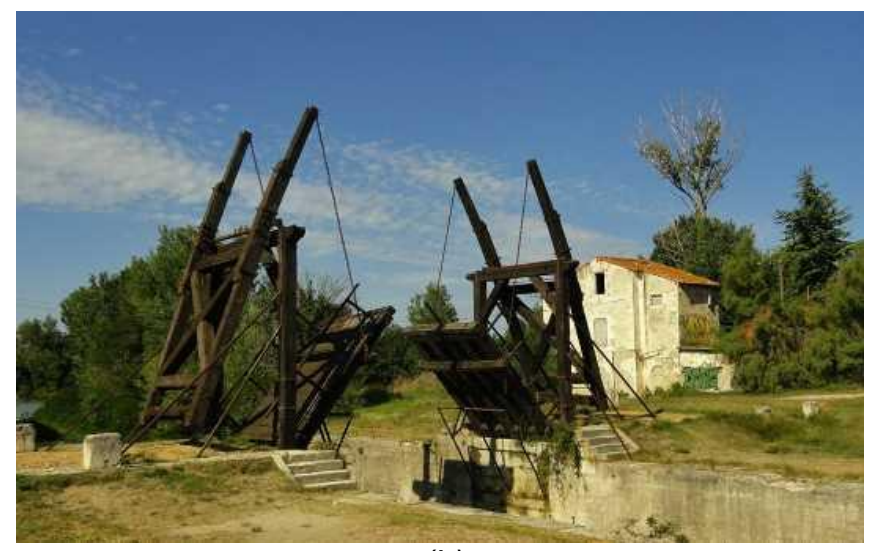

(b)

Fonte: Recuperado de (WIKIPEDIA CONTRIBUTORS, 2020)

Segundo GONZÁLEZ (2019), a diferença entre guindastes contemporâneos e medievais é que eram movidos por seres humanos em vez de combustíveis fósseis, mas o erro é pensar que o que poderia impedi-los é a falta de tecnologia, já que o sistema que usavam era tão funcional quanto o nosso. A diferença real é a quantidade de esforço humano que tal trabalho exigia então, e o esforço que envolve hoje por parte das pessoas. A sociedade atual desenvolve sua tecnologia com o objetivo de minimizar o número de operadores necessários para fazê-la funcionar e fazer seu trabalho no menor tempo possível. $O$ fator tempo é a verdadeira vantagem do mundo contemporâneo que conhecemos hoje.

Ao longo dos tempos, existiram inventores que muito contribuíram com o desenvolvimento da ciência, dentre eles se identifica o Leonardo da Vinci. Um dos seus projetos foi uma espécie de bicicleta, chamada de Eroica, cujos modelos didáticos possibilitam o entendimento dos princípios de funcionamento e proporcionalidade. 


\section{COBENGE $2021 \begin{aligned} & \text { e IV Simpósio Internacional } \\ & \text { de Educação em Engenharia } \\ & \text { da ABENGE }\end{aligned}$ 28 a 30 de SETEMBRO \\ * Evento Online \\ "Formação em Engenharia: Tecnologia, Inovação e Sustentabilidade"'}
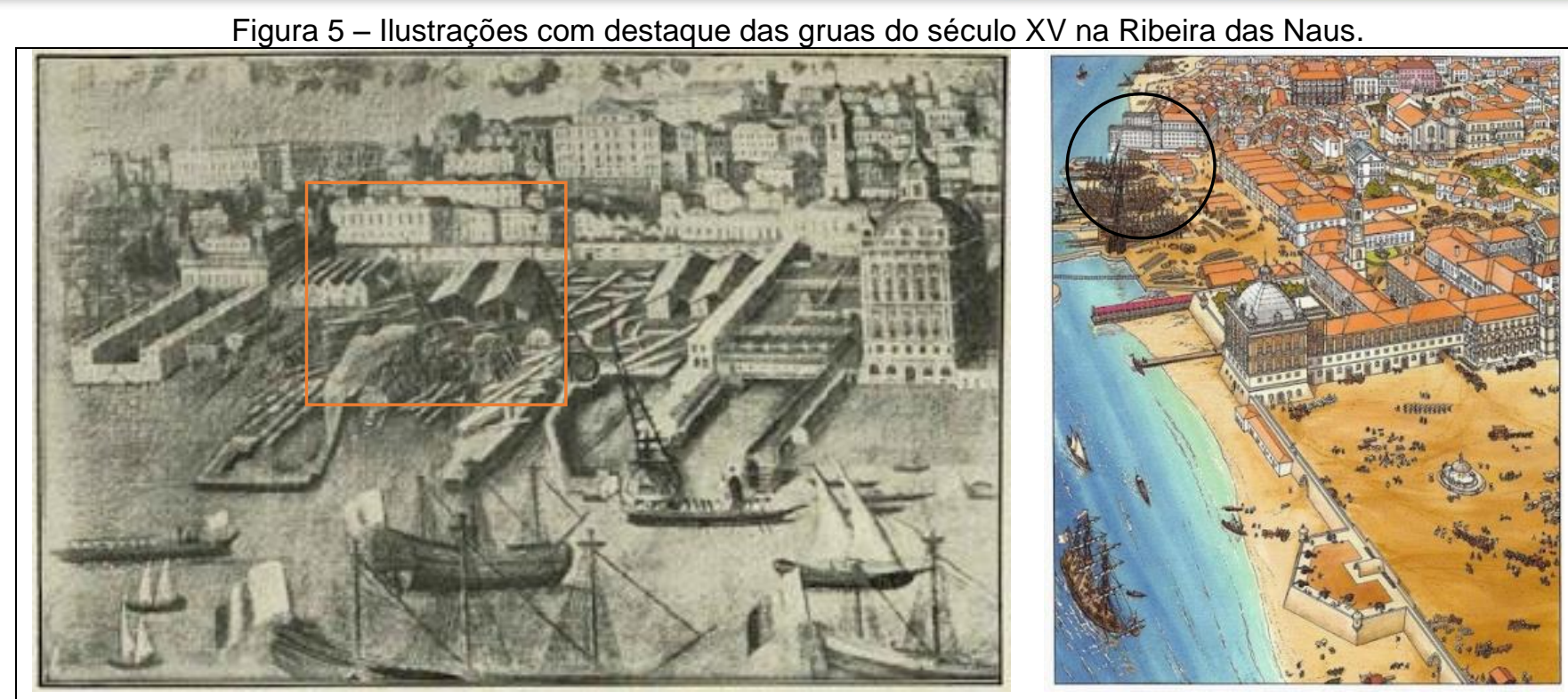

Fonte: Recuperado e adaptado de (CRUZ, 2015).

Figura 6 - Máquina Elevadora Romana.

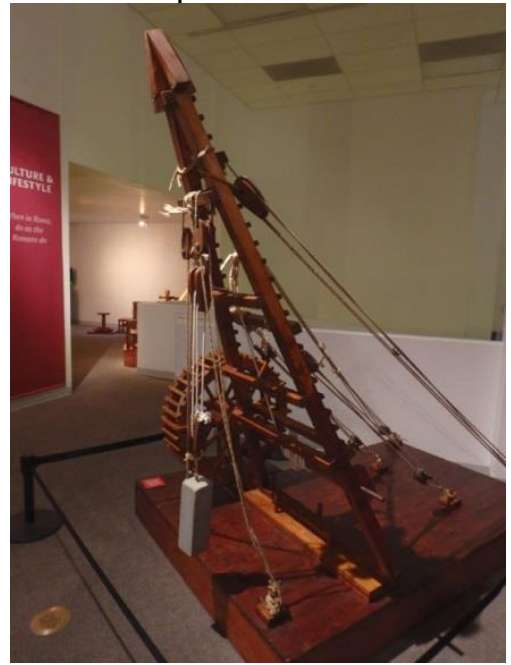

Fonte: Recuperado de (ARTISANS OF FLORENCE, 2020)

Figura 8 - Desenho atribuído a um discípulo de Leonardo da Vinci.

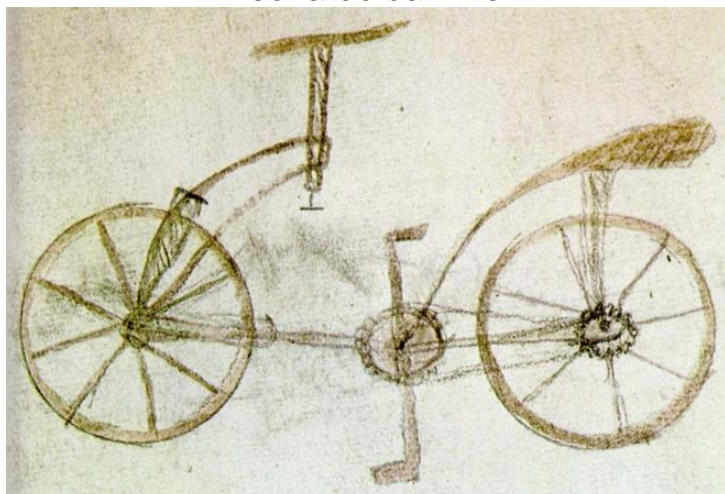

Fonte: Codex Atlânticus (BIBLIOTECA AMBROSIANA, 1493)
Figura 7 - Moinho de água Romano séc. III a.C

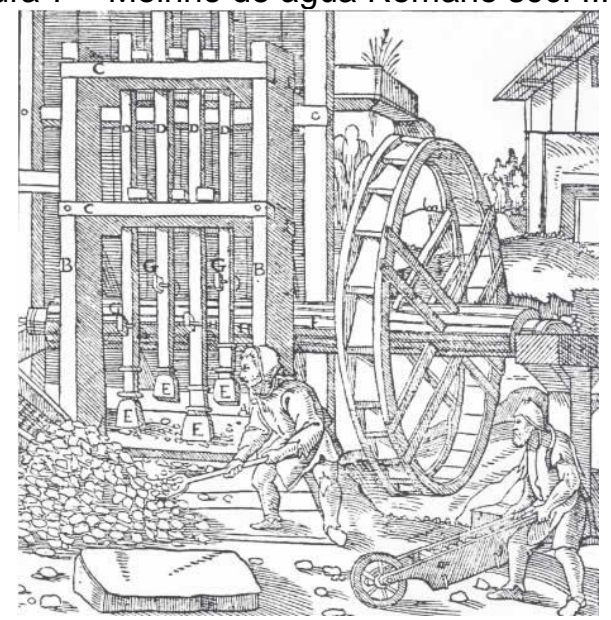

Fonte: Georgius Agricola's De Re Metallica (1556). apud (ROGER D. HANSEN)

Figura 9 - Réplica de um Bate-Estaca Romana.

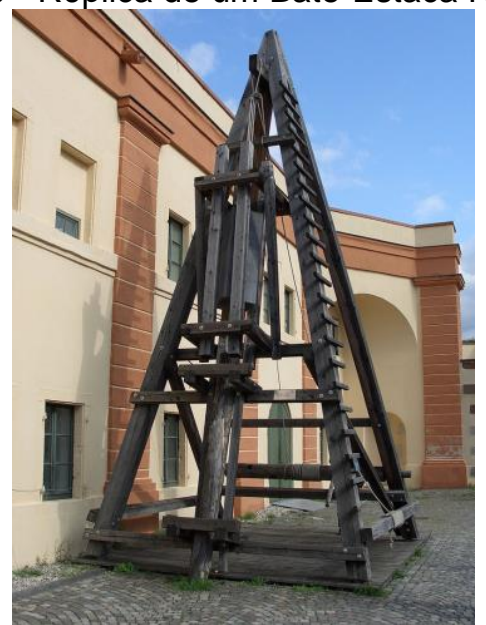

Fonte: Adaptado (WIKIPÉDIA, 2016) 


\subsection{Projetos dos modelos reduzidos}

A proposta do trabalho partiu da condição que os modelos ancestrais deveriam ser projetados a luz das informações remanescestes que pudessem ser obtidas de pesquisas arqueológicas que se encontram disponíveis na rede mundial de computadores. E a escala deveria permitir que eles fossem alojados em salas de aula, possibilitando o contato dos demais alunos da graduação com as reproduções dos mecanismos e estruturas. Para identificação das medidas originais dos elementos, em alguns casos foi utilizada a proporcionalidade com os personagens e/ou objetos representados nas ilustrações disponíveis (Figuras 10, 11 e 12). No caso da Ponte de Langlois, por exemplo, além das pinturas e desenhos de Vincent van Gogh (Figuras 13), que reproduz a cena do local de ângulos diferenciados, também foi possível usar informações de imagens on-line, por se tratar de um elemento ainda existente na cidade de Arles, na França (Figura 14).

Figura 10 - Estudos dos elementos do projeto da Ponte de Langlois.

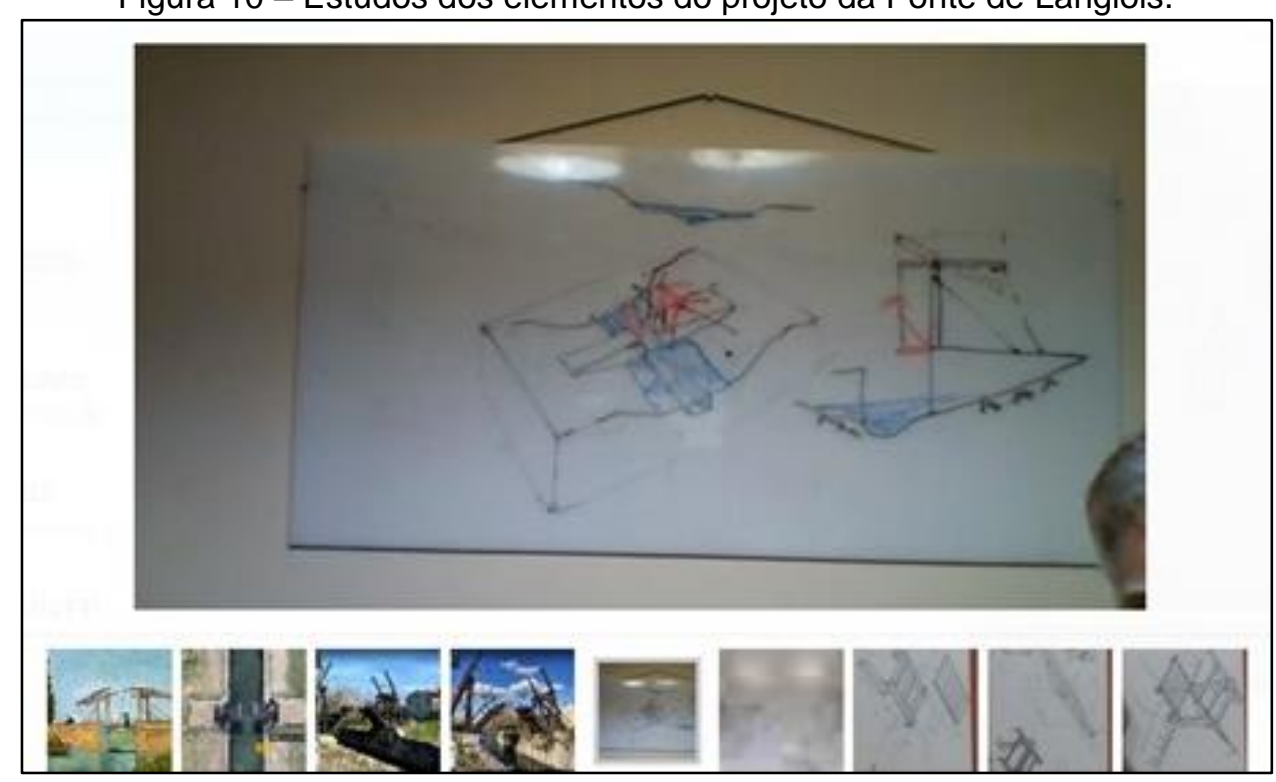

Figura 11 - Dimensionamento dos elementos do projeto da Ponte de Langlois.

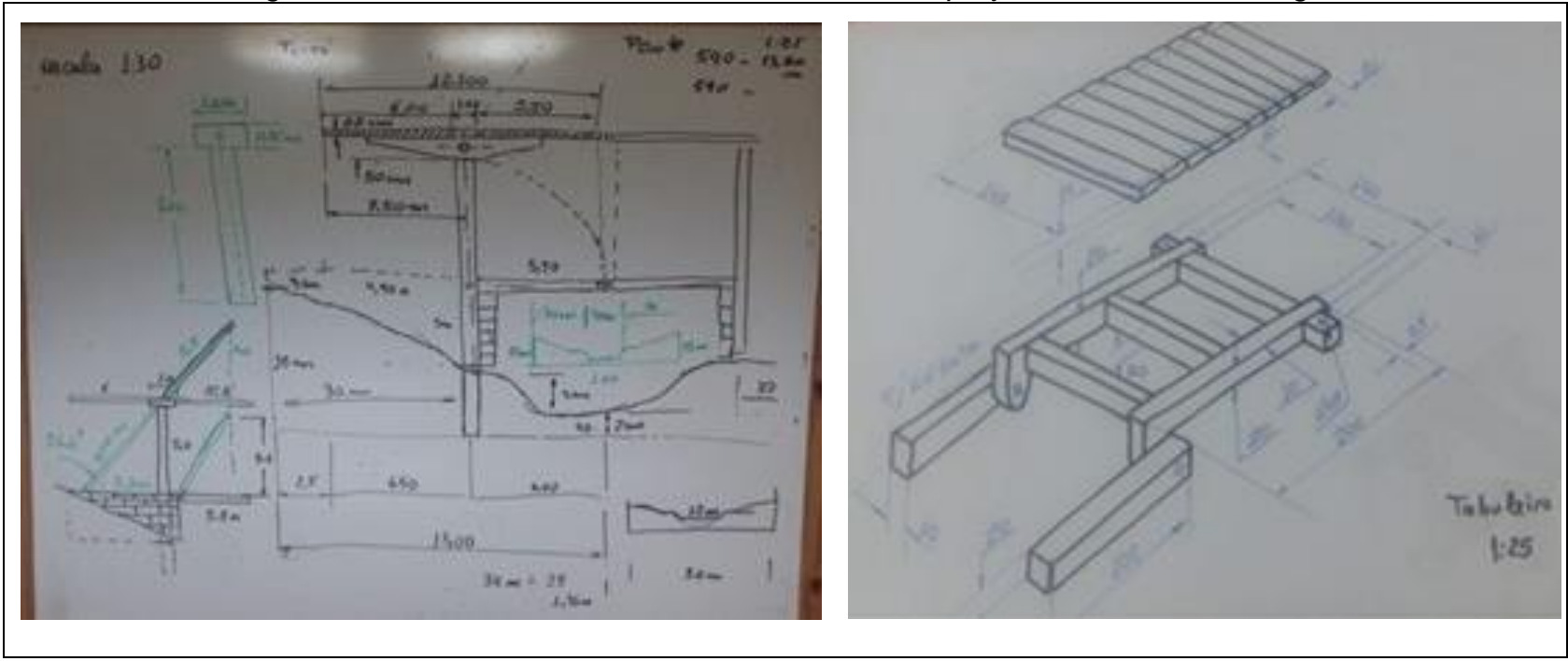




\section{COBENGE de Educação em Engenharia da $A B E N G E$ \\ 28 a 30 de SETEMBRO \\ Evento Online \\ "Formação em Engenharia: Tecnologia, Inovaçáo e Sustentabilidade"}

Figura 12 - Detalhamento dos elementos do projeto da Ponte de Langlois.

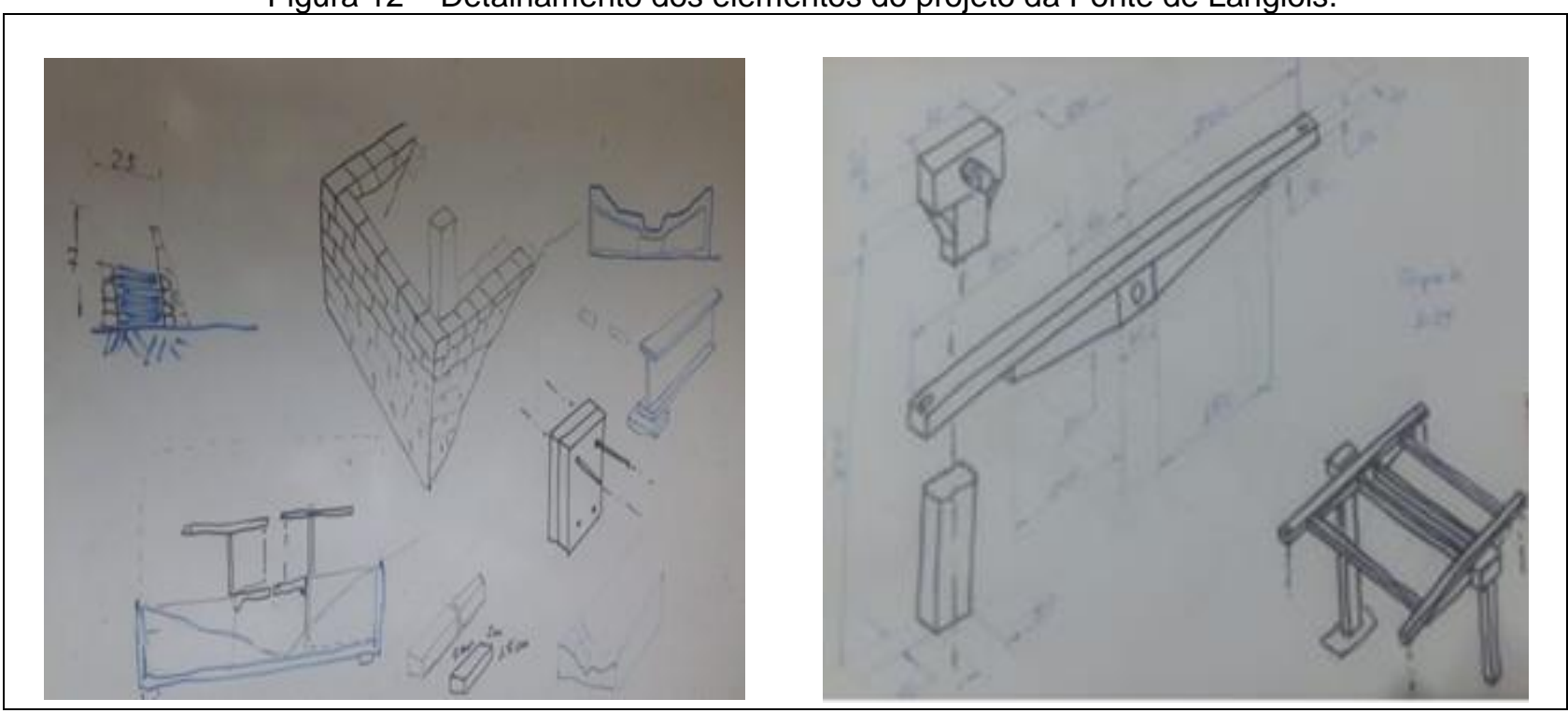

Figura 13 - Quadros de Vincent van Gogh
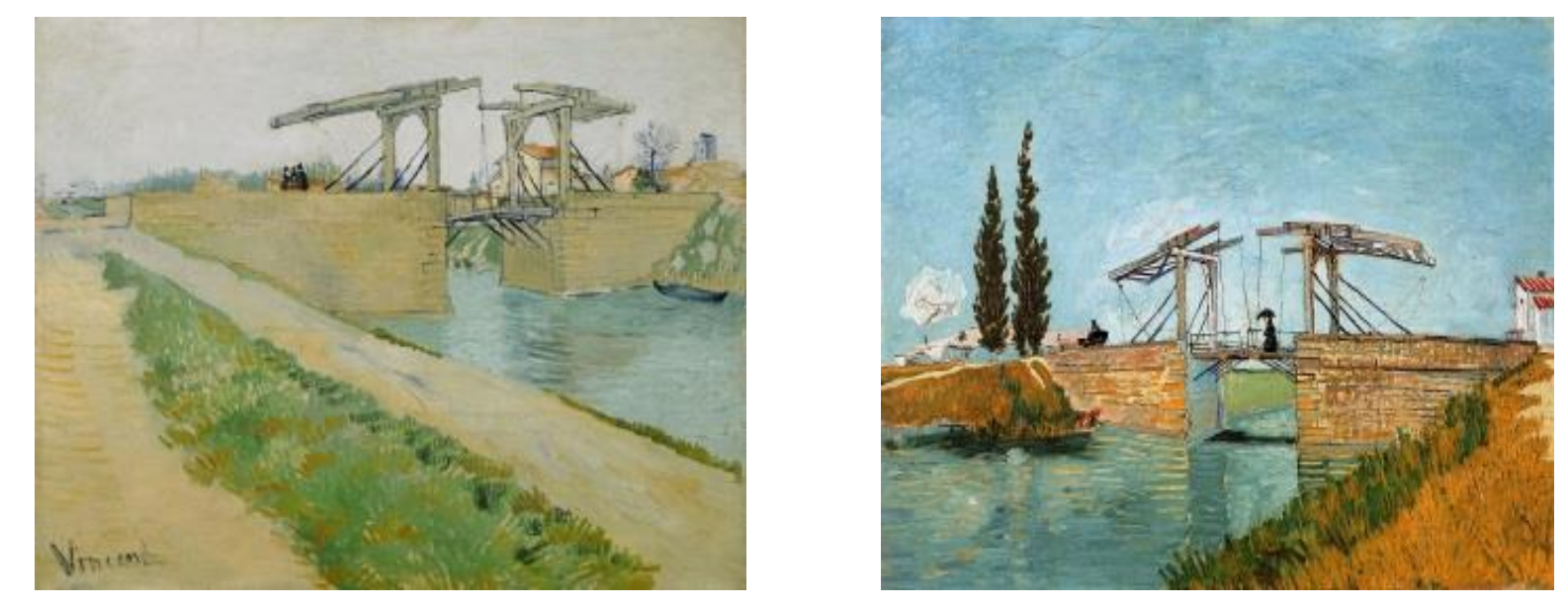

Fonte: Recuperado de (WIKIPEDIA CONTRIBUTORS, 2020)

Figura 14 - Imagem obtida por satélite da atual Ponte de Langlois (GOOGLE MAPS, 2021)

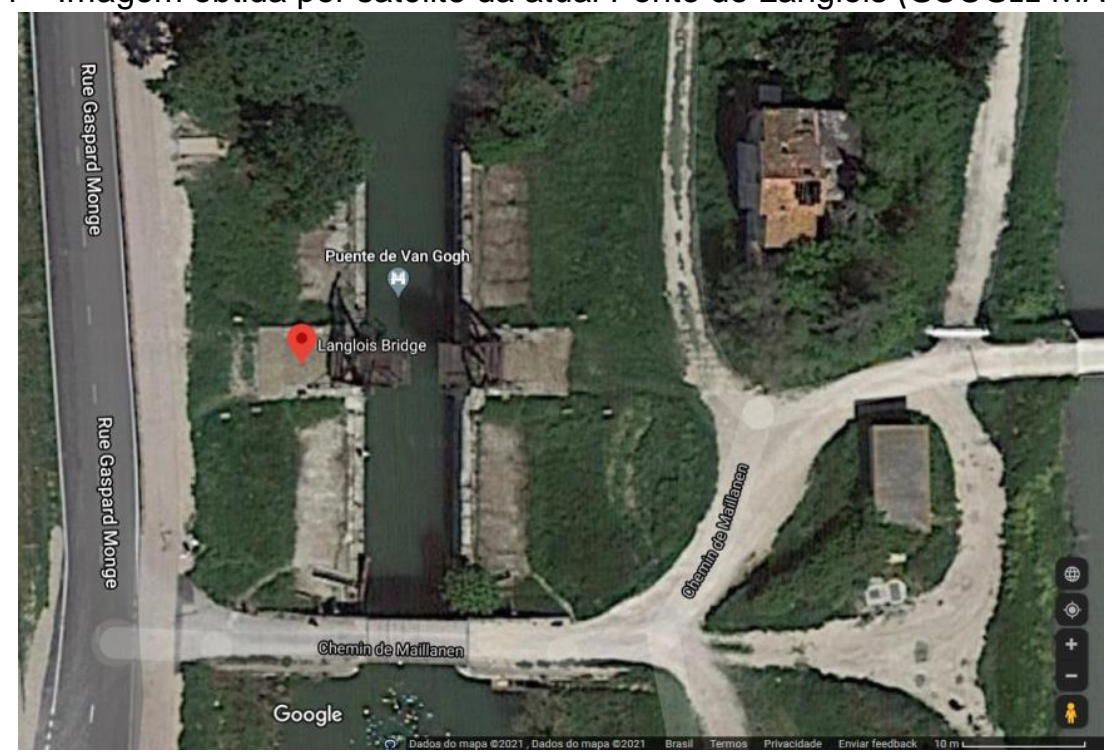


Após o levantamento dos dados, os projetos foram então elaborados utilizando software do tipo CAD (Computer-Aided Design), permitindo tanto a produção das peças em desenho técnico em duas dimensões quanto a criação dos modelos tridimensionais. Exemplos dos projetos realizados na primeira fase são mostrados nas Figuras 15 a 18.

Figura 15 - Projeto da Grua do séc. XV

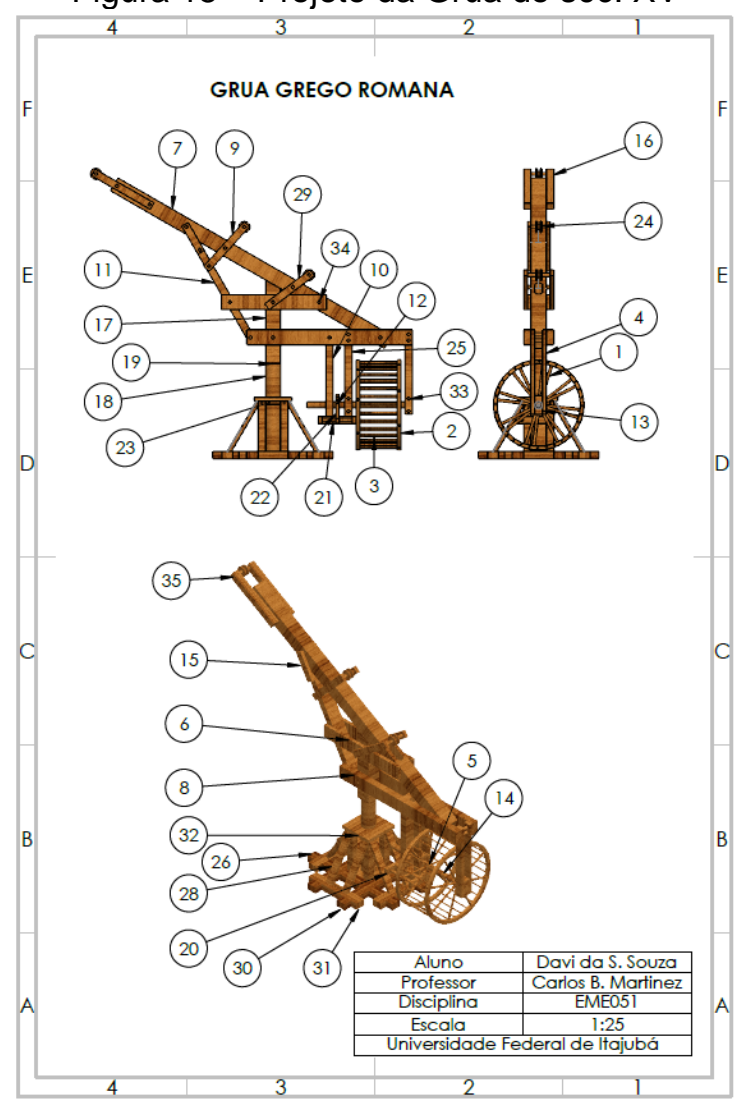

Figura 16 - Projeto Bate-Estaca Romano

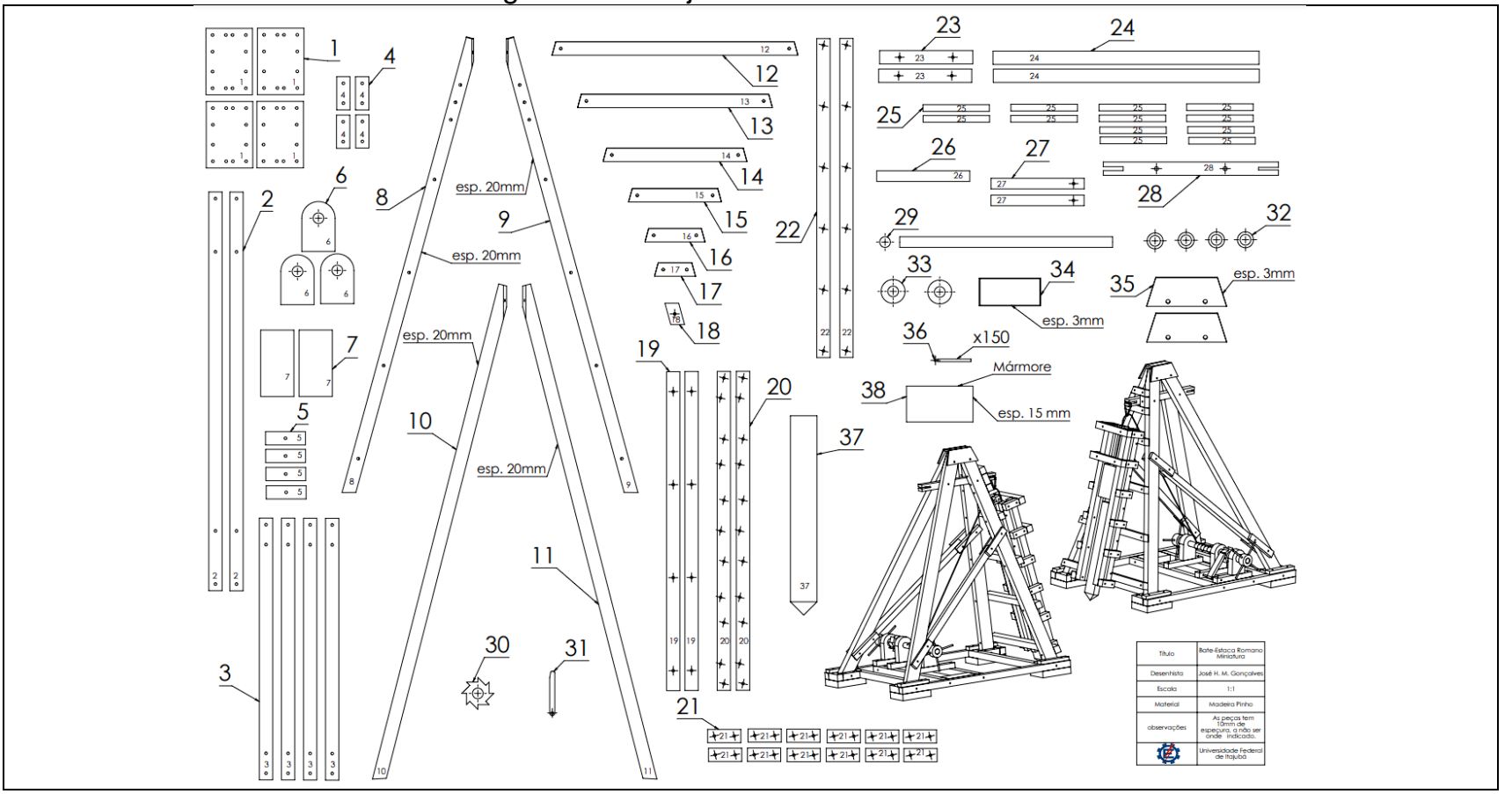


Figura 17 - Projeto da Máquina Elevadora Romana com detalhamento das peças

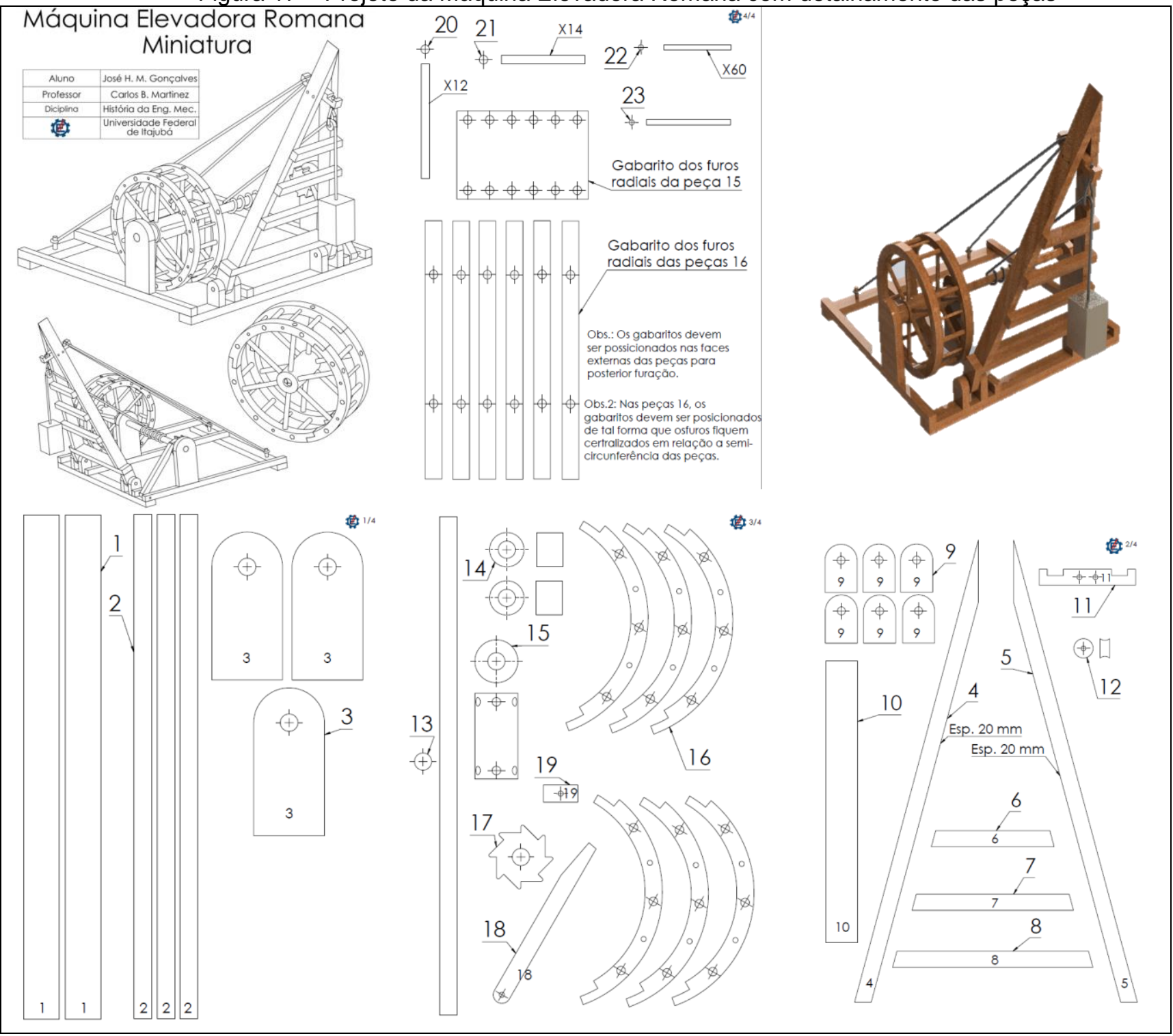

Figura 18 - Projeto da Bicicleta de Da Vinci (a) folha 1 (b) folha 2
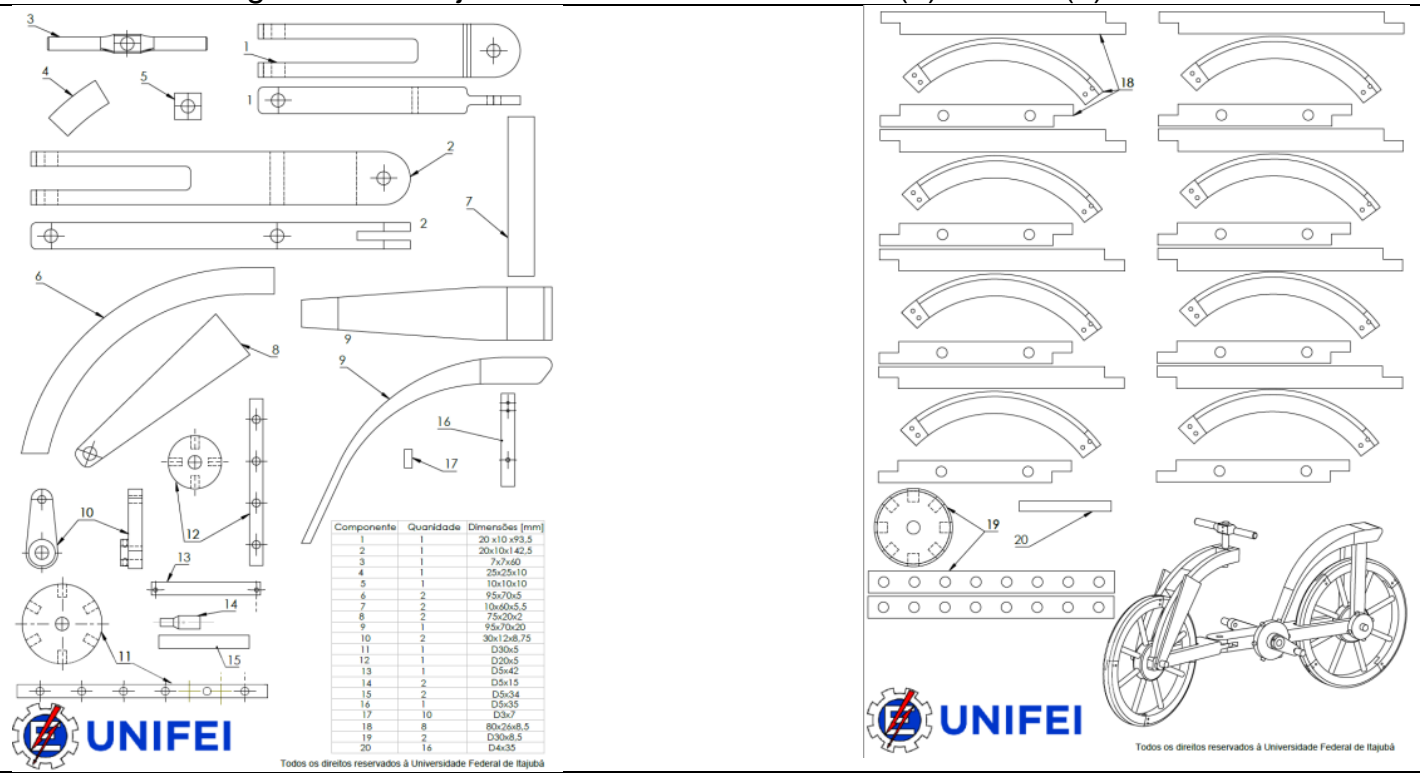


\subsection{Confecção das peças históricas}

Para a montagem dos equipamentos e sistemas ancestrais foram selecionados os materiais de construção de forma que estes fossem compatíveis com os materiais existentes à época a ser representada e facilmente encontrados no mercado. Nesta primeira fase, o principal material usado na construção dos modelos reduzidos foi a madeira (Figura 19). A madeira foi, provavelmente, o material mais utilizado no passado, porque era encontrada em abundância em quase todas as regiões do planeta e também apresentava relativa facilidade de manuseio (TAGLIANI, 2017). Os primeiros guindastes eram feitos de madeira, mas, com a Revolução Industrial, passaram a ser produzidos com ferro fundido e aço. Os guindastes foram inventados na Idade Antiga pelos gregos e eram movidos por homens e/ou animais de carga. Guindastes maiores foram desenvolvidos posteriormente usando engrenagens movidas por tração humana, permitindo a elevação de cargas mais pesadas. Na Alta Idade Média, guindastes portuários foram introduzidos para carregamentos, descarregamentos e construções de embarcações - alguns eram construídos sobre torres de pedra para estabilidade e capacidade extras. Atualmente, o guindaste é constituído normalmente por uma torre equipada com cabos e roldanas que é usada para levantar e baixar materiais (WIKIMEDIA, 2012)

Figura 19 - Construção dos modelos reduzidos em madeira

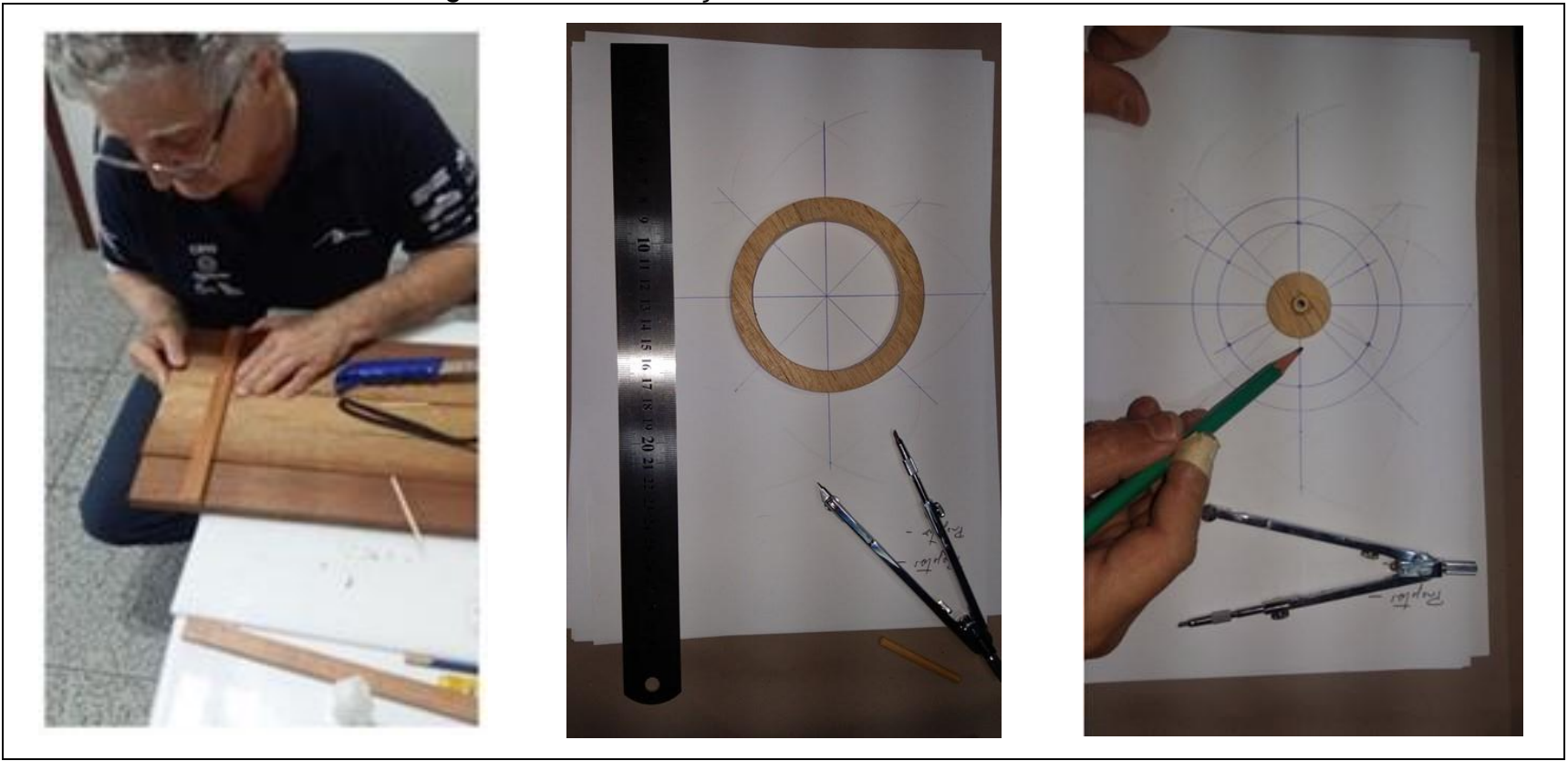

\section{RESULTADOS}

No modelo físico pode-se estudar também, em escala reduzida ou ampliada, diversos fenômenos físicos e utilizá-lo como referência para a calibração de modelos matemáticos. A construção de modelos físicos, em escalas reduzidas, embora estudada anteriormente por Arquimedes, Leonardo Da Vinci, entre outros, só foi possível após a descoberta da Teoria da Semelhança Mecânica por Isaac Newton e do Teorema de Buckingham. Para que um modelo possa representar o protótipo e que os resultados dos ensaios com modelos possam ser entendidos em relação aos protótipos, é preciso que haja semelhança, a começar pela semelhança geométrica (TICONA MELO, 2011). 


\section{COBENCE 2021 le $\begin{aligned} & \text { e IV Simpósio Internacional } \\ & \text { de Educação em Engenharia } \\ & \text { da ABENGE }\end{aligned}$ 28 a 30 de SETEMBRO \\ Evento Online \\ "Formaçāo em Engenharia: Tecnologia, Inovação e Sustentabilidade"}

Nas Figuras 20, 21 e 22 são apresentados exemplos dos modelos reduzidos construídos em semelhança geométrica, de acordo com os projetos elaborados durante as disciplinas.

Figura 21 - Modelo reduzido do Bate-Estaca Romana

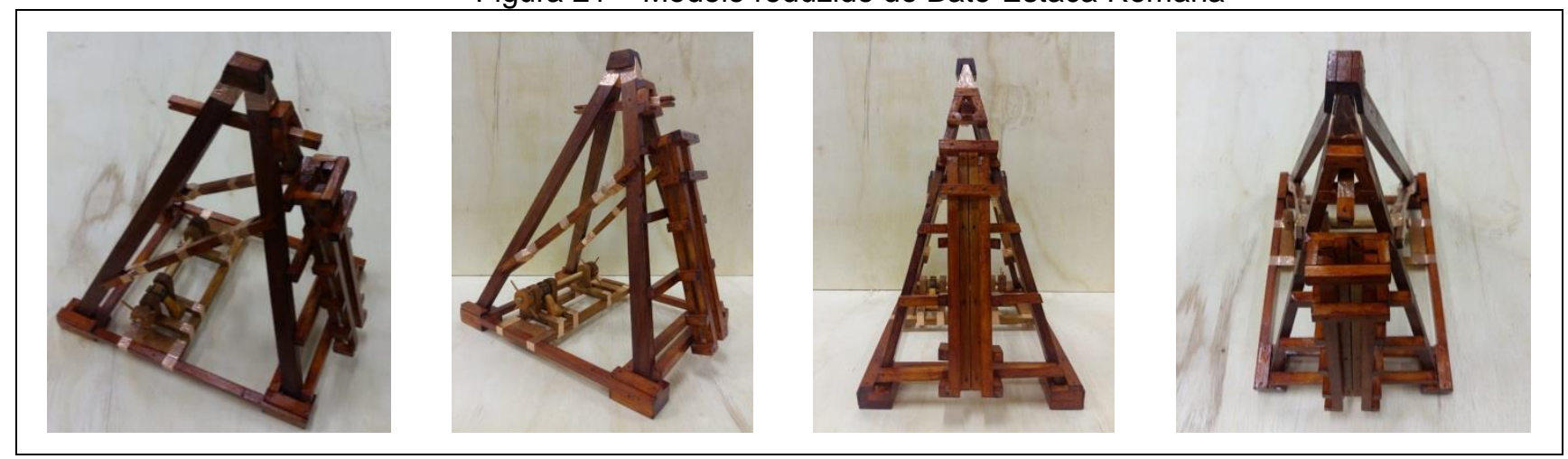

Figura 20 - Modelo reduzido da Ponte de Langlois

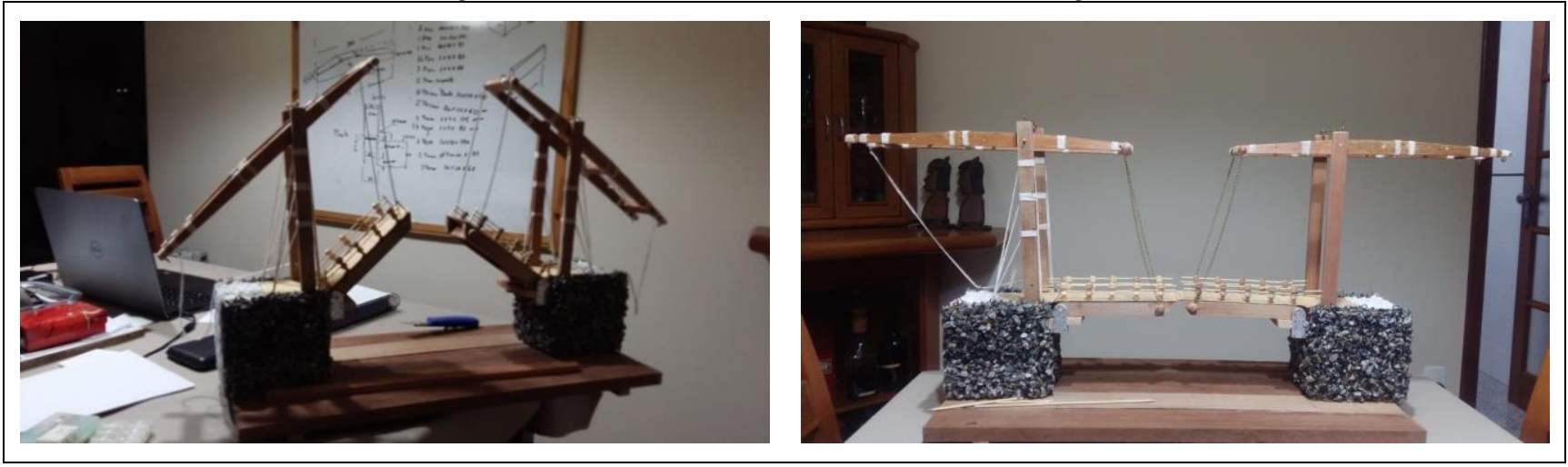

Figura 22 - Modelo reduzidos da Bicicleta de Da Vinci (a) vista lateral e (b) vista em ângulo

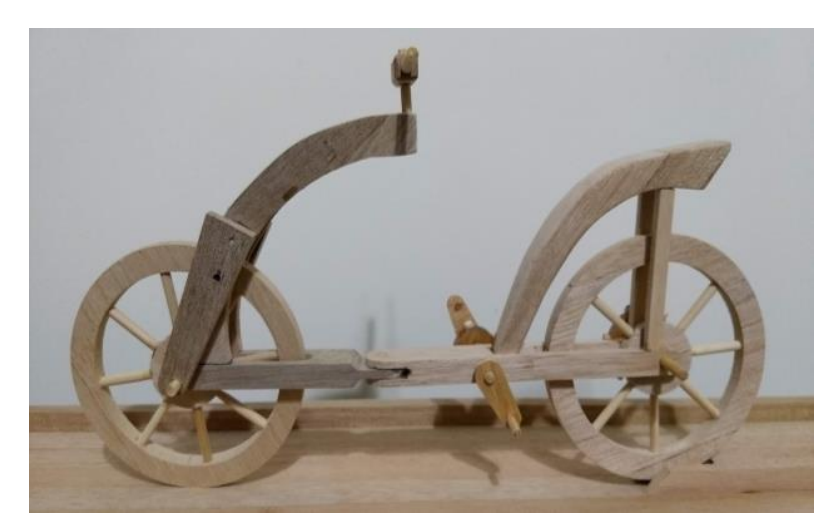

(a)

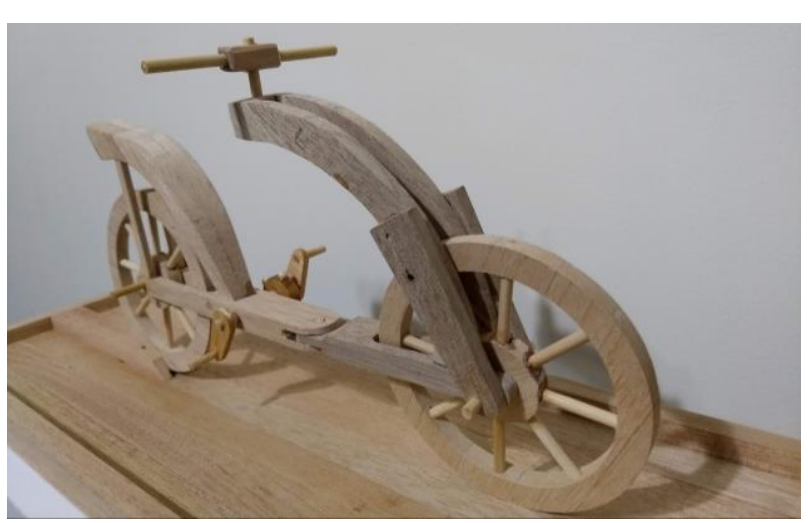

(b)

\section{CONSIDERAÇÕES FINAIS}

O conhecimento dos sistemas e equipamentos produzidos pelo esforço dos engenheiros da antiguidade, suas transformações e tendências ao longo da história, permitem entender como as soluções existentes se tornaram possíveis. As máquinas e sistemas ancestrais construídos neste projeto deram início a um conjunto de pequenas estruturas que constituem o núcleo de uma coleção que ficará à disposição de professores dos cursos de graduação em engenharia e que poderão ser utilizados nas 
aulas como ferramenta de ensino. Pretende-se que no futuro esses modelos possam ser expostos no Museu Theodomiro Santiago / Itajubá - MG, que pertence ao complexo histórico e cultural da UNIFEI, possibilitando a visualização deles pelo público em geral, como forma de conquistar mais alunos para os cursos de engenharia.

As peças produzidas compõem um acervo técnico inédito na UNIFEI e permitiram ao grupo de alunos envolvidos entenderem algumas das limitações do passado, visualizando os caminhos adotados e as soluções encontradas pelos engenheiros em diversas épocas da nossa história.

\section{Agradecimentos}

Agradecemos a Universidade Federal de Itajubá (UNIFEI) por proporcionar as condições essenciais para o desenvolvimento deste trabalho. E também aos alunos Davi Veloso Alves, Guilherme Naback Zambroni e Davi da SilvaSouza pela participação no projeto.

\section{REFERÊNCIAS}

ADAM, J. P.. Roman Building - Materials and Techniques. London: B.T.Batsford Ltd, 1994.

ARTISANS OF FLORENCE. https://www.artisansofflorence.com/, 2020. Acesso em: 29 mar. 2021.

BAZZO, W. A.; PEREIRA, L. T. V. Introdução à Engenharia: conceitos, ferramentas e comportamentos. Florianópolis: UFSC, 2006.

BIBLIOTECA AMBROSIANA. Codex Atlânticus. Milão: [s.n.], 1493.

BRITANNICA. Archimedes screw. [S.I.]: Encyclopedia Britannica, , 2014. Disponivel em: <https://www.britannica.com/technology/Archimedes-screw>. Acesso em: 06 april 2021.

CCFEX. Centro de Capacitação Física do Exército e Fortaleza de São João, 2017. Disponivel em:

<http://www.ccfex.eb.mil.br/images/2019/blomefield12lb/blomefield1.jpg>. Acesso em: 29 mar. 2021.

CECCARELLI, M. E. A. Design and Reconstruction of an Ancient Roman Crane. Advances in Historical Studies, v. 9, p. 261, 2020. ISSN 05. Disponivel em: <https://www.scirp.org/journal/ahs>.

CRUZ, P. Marinha de Guerra Portuguesa - Ribeira das Naus - XVI - XVIII, 01 abr. 2015. Disponivel em: <http://marinhadeguerraportuguesa.blogspot.com/2015/03/ribeira-das-naus-xvi-xviii.html>. Acesso em: 05 abr. 2021.

GALLO, I.M. Nuevs elementos de ingeniería Romana. III Congresso de las obras públicas Romanas. Astorga: [s.n.]. 2006.

GONZALÉS, A. S. Reproducción de una grúa romana a escala mediante impresión 3D. [S.I.]: Universitat Politècnica de Catalunya, 2019. Disponivel em:

<https://pt.wikipedia.org/w/index.php?title=Guindaste\&oldid=58537979\%3E.\%20Acesso\%20em:\%2018\%2 0jun.\%202020>. Acesso em: 2021.

GOOGLE MAPS. www.google.com.br/maps/place/. Langlois Bridge, 2021. Disponivel em: <https://www.google.com.br/maps/place/Langlois+Bridge/@43.6569533,4.620962,83m/data=!3m1!1e3!4 $\mathrm{m} 5$ !3m4!1s0x12b676f44dc29cbb:0x6fa70d4b928ebdb3!8m2!3d43.6569469!4d4.6210257>. Acesso em: 30 mar. 2021. 
LEONID NADOLINETS , EUGENE LEVIN , DAULET AKHMEDOV. Surveying Instruments and Technology. Boca Raton: Routledge Handbooks Online., 2017. Acesso em: acessado em 06 abr 2021.

ROGER D. HANSEN. WaterHistory.org. www.waterhistory.org. Disponivel em:

<http://www.waterhistory.org/histories/waterwheels/waterwheel2.small.jpg>. Acesso em: 29 mar. 2021.

RORRES, C. THE TURN OF THE SCREW: OPTIMAL DESIGN OF AN ARCHIMEDES SCREW. Journal of Hydraulic Engineering, p. 9, 2000.

TAGLIANI, S. Saiba quais materiais eram empregados na engenharia da antiguidade., 04 ago. 2017. Disponivel em: <https://engenharia360.com/materiais-engenharia-da-antiguidade>. Acesso em: 05 abr. 2021.

TICONA MELO, L. R. Monitoração de modelos físicos reduzidos para investigação do comportamento de estruturas em escala real. São Paulo: Departamento de Engenharia de Estruturas e Geotécnica, 2011.

WIKIMEDIA. GUINDASTE, 2012. Disponivel em:

<https://pt.wikipedia.org/w/index.php?title=Guindaste\&oldid=58537979>>. Acesso em: 05 abr. 2021.

WIKIPÉDIA. Bate-Estacas, 2016. Disponivel em: <https://pt.wikipedia.org/wiki/Bate-estacas>.

WIKIPEDIA CONTRIBUTORS. Wikipedia, The Free Encyclopedia. Langlois Bridge at Arles, 2020. Disponivel em: <https://en.wikipedia.org/wiki/Langlois_Bridge_at_Arles>. Acesso em: 07 abr. 2021.

\section{STUDIES ON ANCESTRAL MACHINERY AND SYSTEMS IN ENGINEERING AT UNIFEI}

Abstract: The basic principle of operation of ancestral equipment is often the same as the modern systems used in engineering today. Understanding that the solutions used in the past provide strong evidence about engineering alternatives, which can serve to solve contemporary problems and develop skills that facilitate the understanding of current mechanisms and structures, we sought to develop a project involving undergraduate students with the aim of presenting a set of ancestral equipment models, representative of technologies developed by civilizations prior to the present, as a teaching tool in engineering. The students were guided in the development of the activities, distributed in the following stages: (i) selection of a mechanism and / or structure considered representative of a determined time or civilization through bibliographic survey; (ii) elaboration of the designs of the reduced models based on the data collected and (iii) construction and testing of the selected elements. In the first phase of the project, the following equipment was selected, among others: Langlois Bridge, 16th century crane. XV, Roman Lift Machine and century water mill III a.C.. The ancestral machines and systems built in this project started a set of small structures that constitute the nucleus of a collection that will be available to professors of undergraduate engineering courses and that can be used in class as a teaching tool. The pieces produced make up an unprecedented technical collection at UNIFEI and allowed the group of students involved to understand some of the limitations of the past by visualizing the paths adopted and the solutions found by engineers at different times in our history.

Keywords: engineering history, ancestral machines, reduced models. 